\title{
Model-Based Control of Renewable Energy Systems in Buildings
}

\author{
Yi Zhang, PhD \\ Vic I. Hanby, PhD \\ Member ASHRAE
}

Received December 21, 2005; accepted March 24, 2006

\begin{abstract}
This paper describes a research project concerned with the problem of supervisory control of systems that combine a range of heat sources with active and passive thermal storage. The work is based on a prototype building that includes a ventilated photovoltaic array, solar air and water heating, a biomass-fired boiler, and a stratified thermal store.
\end{abstract}

The supervisory control problem is, for each source, whether to deploy the received energy directly into the building, store it for later use, or reject it to the environment. These decisions are currently made by a building management system programmed with a complex, arbitrary set of rules and setpoints. The considerable number of operational states means that such a control system is very difficult to commission. Analysis of the data for the early stages of building operation indicate strongly that it is unlikely optimal use is being made of the renewable energy sources with this approach. The objective of this research is to investigate the potential effectiveness of replacing the rule-based control scheme with one based on a combination of a building/system model with an optimization algorithm.

The existing building, plant, and control systems were modeled using a commercial simulation environment and calibrated against measured data from the building. A period of swing-season operation was used to compare the existing control with that based on an optimal approach. Results indicate that significant improvements in system operation are possible but also that significant improvement in execution time will be needed for any future online deployment.

\section{INTRODUCTION}

This ongoing research project addresses the issue of the control of renewable systems in buildings. Renewable energy sources are generally of low intensity and temporally inconsistent; these characteristics cause particular control problems that must be solved if the integration of renewable energy into buildings is to be effectively exploited. The overall objective of a successful control system must be to maximize the use of renewable energy sources and to minimize the import of external energy, subject to constraints such as the maintenance of satisfactory internal conditions.

To achieve this objective, top-level supervisory control is necessary. The supervisory control must be able to monitor the states and demands in the system and adjust control variables (setpoints and actuators) accordingly to suit the dynamics of the system. This requires two aspects of the system to be studied: the dynamic interaction of renewable energy systems with the building in order to understand the behavior of the complete system and an effective methodology for implementing dynamic optimized control. 
In the following sections of this paper, the prototype building and its renewable energy systems are introduced and the development of the dynamic models of the building and plant is described. We then discuss the behavior of the present building energy management system (BEMS) control strategies, which serve as a benchmark and show that significant improvements in the performance of the energy systems are possible with a combined modeling-optimization approach.

\section{BACKGROUND}

The use of system models to improve the performance of supervisory control systems is not a new idea, early work having emerged two decades ago (Kelly 1988). The first approach suffered from the same limitations as early attempts to link simulations with optimization routines in a design context (Wright and Hanby 1987), namely, limitations imposed by the available computing power. The key defining characteristics of the problem are the number of control variables and the time horizon over which the problem is to be analyzed. There are two important considerations: the execution time of the model combined with the efficiency of the search method. There is no realistic situation in which an exhaustive (parametric) search can be applied in this context; hence, a critical characteristic of a candidate optimization method is its ability to reduce the size of the search space, in particular to find optimal or near-optimal solutions with economy of calls to the simulation. Extensive work preceding this project has shown that, in contrast to the solution of classical test problems, the processor time used within the search algorithm is negligible compared with the time taken to evaluate the function (i.e., run the simulation). The consequence of this is that the overriding criterion for evaluating the effectiveness of a search algorithm in this context is economy of function calls to the building/system model (Fong et al. 2005).

The more tractable class of problems includes those in which an optimization is run in real time, using current input data, in order to produce a set of control signals for the next time period. A good example of this approach has been described by Wang and Jin (2000), Sun and Reddy (2005), and Van Schijndel (2002). The problem size escalates significantly where, due to active and/or passive storage effects, the analysis needs to be projected into the future to generate a control trajectory. The horizon typically will be determined by such factors as occupancy, diurnal cycles, or the time constants associated with the building or its systems.

The optimization of the performance of a hollow, ventilated concrete slab has been described by Ren and Wright (1997). The control variables included scheduling (on/off decisions) together with setpoints and flow rates. The work highlighted the importance of the accuracy of modeling the system. Morris et al. (1994) evaluated the potential for optimal control that was able to account for passive thermal storage in a building. Keeney and Braun (1996) showed that a large proportion of the potential energy savings could be achieved using a simplified control strategy that was far less computationally intensive. Optimization of a combination of an active ice store with passive thermal storage in the building has recently been described by Henze et al. (2005). This produced control trajectories over a 24-hour period using a detailed system model, but the work was compromised by the optimization converging on local minima.

The objective of this investigation was to evaluate the potential for optimal supervisory control of a building/system that included both active and passive thermal storage combined with an array of comparatively novel renewable energy systems. A problem here is in devising a benchmark from which to measure any performance improvement. There are no published, established control strategies against which to calibrate performance; hence, the baseline adopted was the supervisory control design implemented by the HVAC designers for this prototype building. 


\section{BROCKS HILL ENVIRONMENT CENTRE}

The Brocks Hill Environment Centre (Cartmell 2004) is the centerpiece of the Brocks Hill country park in the city of Leicester, UK. It is a local authority-owned building designed to promote public awareness of renewable energy and some other aspects of sustainable practice. The design of the building reflects the considerations of daylight penetration, natural ventilation, and the use of solar radiation for wintertime space heating. The building has also been designed to be thermally massive and is insulated to meet much higher standards than the requirements of the present UK Building Regulations. The thermal systems in the building make use of renewable energy from solar air and water heating and from burning biomass collected from the surrounding woodland. A $20 \mathrm{~m}^{2}$ evacuated tube solar water (SW) collector and a ventilated photovoltaic array and solar air (VPV/SA) collector of total area $36.2 \mathrm{~m}^{2}$ are installed, together with a $19 \mathrm{~kW}$ dual-fuel (35 sec oil/biomass) boiler. At the center of the system, a 1000 litre stratified hot water storage tank is used as a hub connecting the heating and hot water circuits. Heated water from the boiler, the solar water collector, and the solar air collector heat exchanger is stored in the tank, which supplies a heating coil in the air-handling unit (AHU) and a separate domestic hot water cylinder.

The internal space of the building has been divided into three heated zones: an exhibition hall, a classroom, and a restaurant area. The heating and ventilation system consists of an AHU with a sensible heat recovery exchanger and a separate circuit for the VPV/SA collectors. The VPV/SA circuit can operate in one of the following four modes: preheating the inlet air to the $\mathrm{AHU}$, as a closed circulation loop transporting heat to storage via an air-water heat exchanger, as an open circuit cooling the PV panels, or turned off. The AHU has a supply fan, an extract fan, and a heating coil. The air and water circuits are shown in Figures 1 and 2.

The operation of the system is controlled by a centralized BEMS. The control strategies were designed and commissioned in a steady-state context, the operational mode of the system being decided by a set of predefined setpoints. This implies that there may be scope for improvement because the dynamics of the energy systems and the building are not taken into account.

\section{SIMULATION ENVIRONMENT}

The Matlab/Simulink ${ }^{\circledR}$ environment (Mathworks 2005) has been widely used in dynamic system modeling in many engineering fields, especially where control technology is needed. The following factors were relevant to the use of these programs in this work:

- A wide range of mathematical libraries is provided.

- An extensive collection of components for modeling continuous, discontinuous, and discrete systems is available. It is possible to build a system model using graphical components. In this way, complex models are easier to understand and maintain.

- A variety of ordinary differential equation (ODE) solvers are provided for different types of system dynamics. Models developed in other languages can be imported into this environment.

- A real-time interface is available for linking with control hardware.

\section{BUILDING THERMAL MODEL}

A major challenge in this project was the development of component and subsystem models for the building thermal systems. Although the building itself had been modeled in detail at the design stage (Cartmell 2004), it was decided to use a simplified model to represent the three conditioned zones. For computational efficiency it was decided to use a simplified zone thermal model, the implementation of which is shown in Figure 3. Each zone is represented by two tem- 


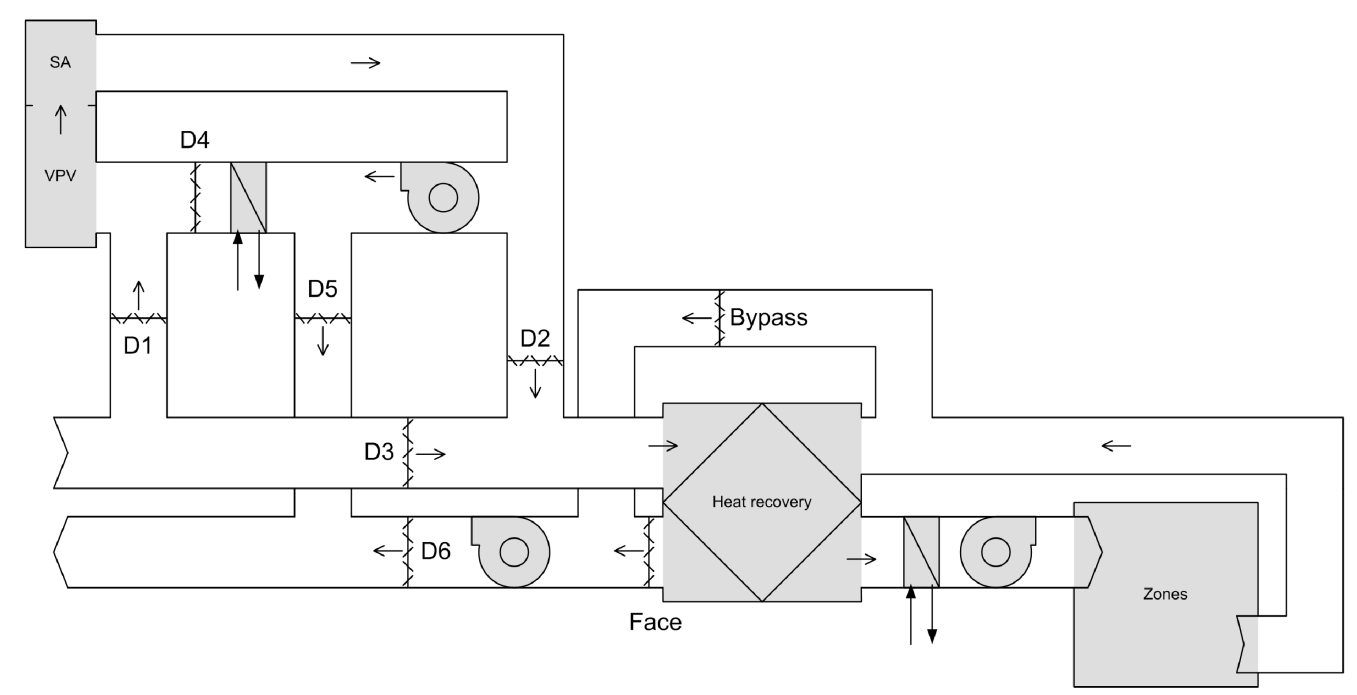

Figure 1. Diagram of air system in Brocks Hill Environment Centre ("D" denotes dampers).

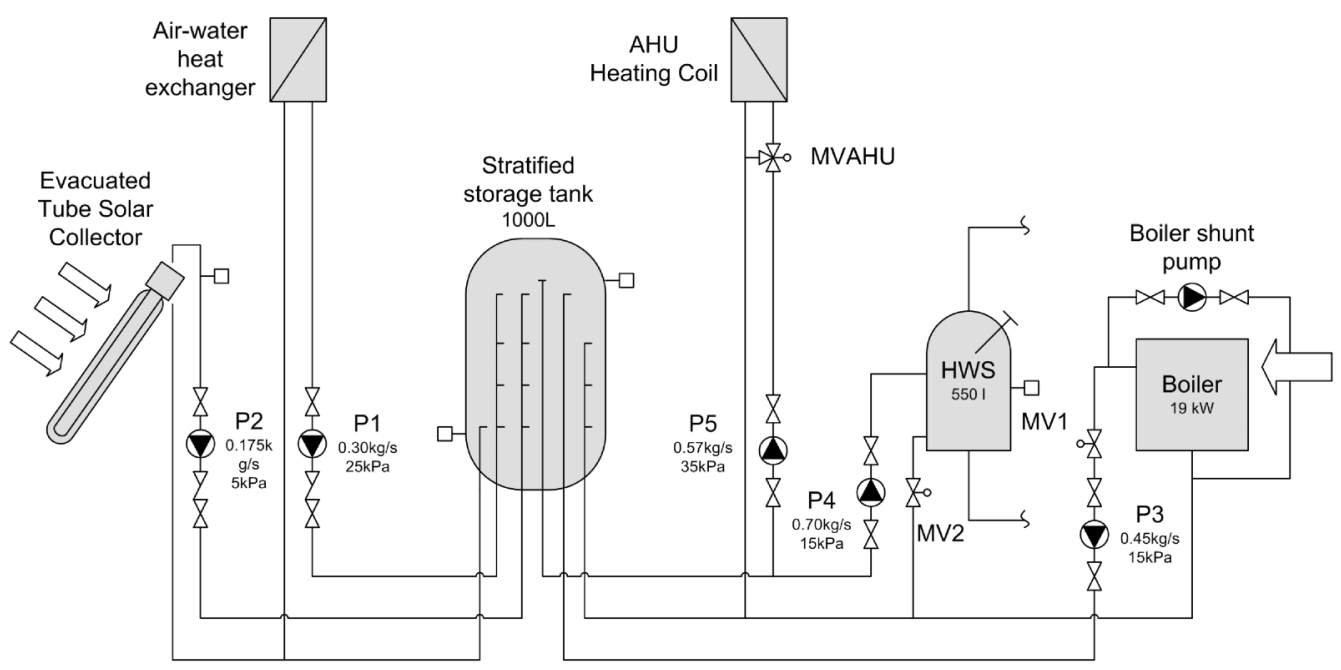

Figure 2. Diagram of water system in Brocks Hill Environment Centre ("P" denotes pumps; "MV" denotes motorized valves).

perature nodes and is characterized by five parameters. As the project was not concerned with short-term transients, which would be important in local loop control, this model was judged to give adequate integrity combined with computational efficiency. Experience has shown that large plant models are generally computationally demanding and that it is difficult to make such compromises in this area. The model was originally introduced in the UK by Crabb et al. (1987); it has two dynamic temperature nodes broadly representing the air and a lumped structure node. Two dynamic heat balance equations are used: 


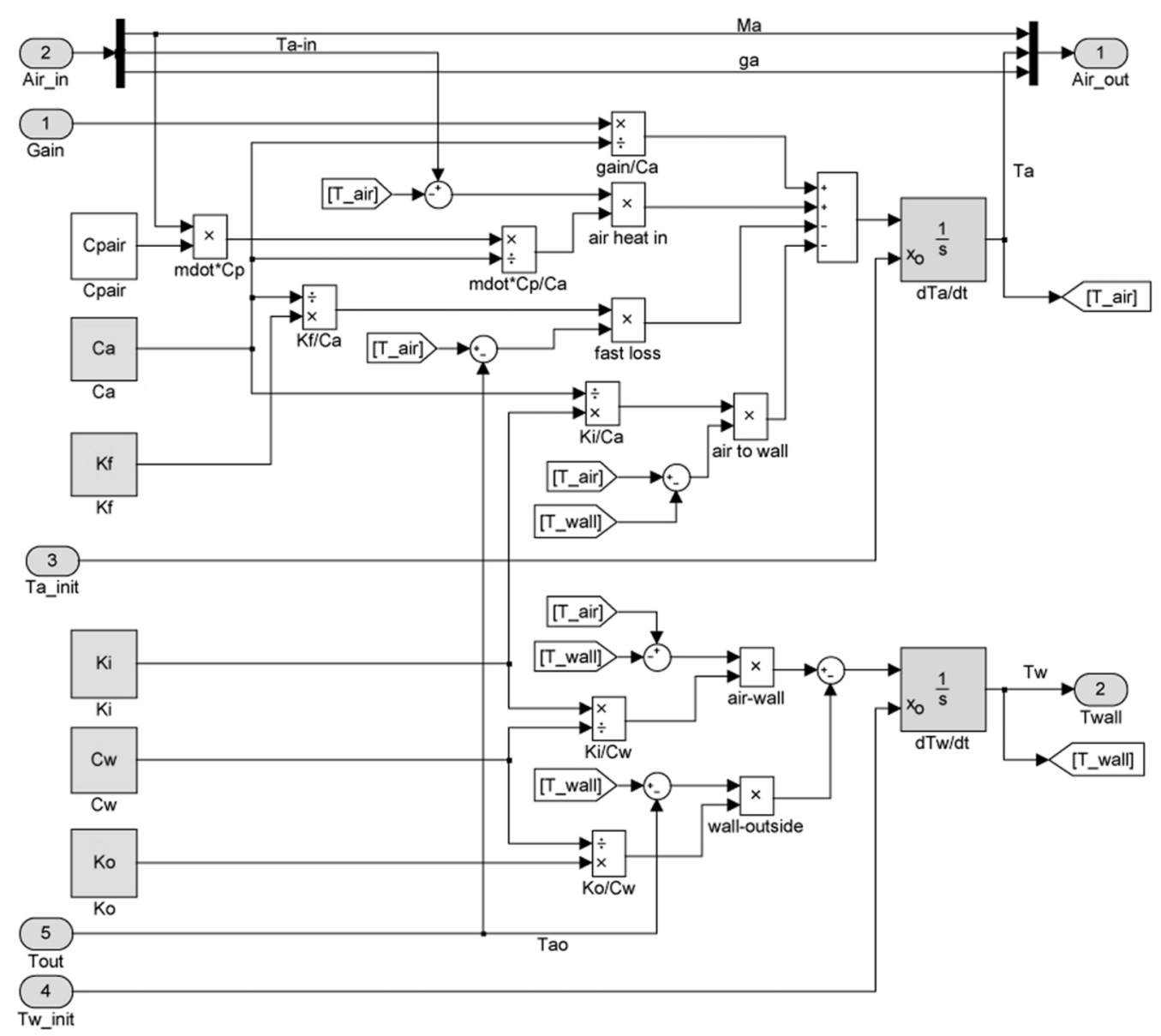

Figure 3. Implementation of simplified zone model.

$$
\begin{gathered}
C_{a} \frac{d T_{a}}{d t}=Q-K_{i}\left(T_{a}-T_{w}\right)-K_{f}\left(T_{a}-T_{o}\right) \\
C_{w} \frac{d T_{w}}{d t}=K_{i}\left(T_{a}-T_{w}\right)-K_{o}\left(T_{w}-T_{o}\right)
\end{gathered}
$$

where

$T_{a}=$ air temperature $\left({ }^{\circ} \mathrm{C},{ }^{\circ} \mathrm{F}\right)$

$T_{w}=$ mean wall (structure) temperature $\left({ }^{\circ} \mathrm{C},{ }^{\circ} \mathrm{F}\right)$

$T_{o}=$ outside air temperature $\left({ }^{\circ} \mathrm{C},{ }^{\circ} \mathrm{F}\right)$

$Q=$ heat input to the air node $(\mathrm{kW})$ (This has three components: the heat input to the zone via the warm air terminals $\left(Q_{i}\right)$, casual gains from the occupants and electrical equipment $\left(Q_{c}\right)$, and solar gain $\left(Q_{s}\right)$; see Equations 3-6.)

$$
\begin{gathered}
Q=Q_{i}+Q_{c}+Q_{s}[\mathrm{~kW}] \\
Q_{i}=\dot{M}_{a} C_{p}\left(T_{s}-T_{a}\right)[\mathrm{kW}]
\end{gathered}
$$


where

$M_{a}=$ supplied air mass flow rate $(\mathrm{kg} / \mathrm{s})$

$C p=$ specific heat of air $(\mathrm{kJ} / \mathrm{kg} / \mathrm{K})$

$T_{S}=$ supplied air temperature $\left({ }^{\circ} \mathrm{C},{ }^{\circ} \mathrm{F}\right)$

The casual gain $\left(Q_{c}\right)$ was considered as a boundary variable during the occupied hours:

$$
Q_{c}=F_{c} \cdot 1.0[\mathrm{~kW}]
$$

where

$F_{c}=$ casual gain factor

The solar gain $\left(Q_{S}\right)$ was treated as a gain factor relating the gain to the zone to the global solar radiation intensity on the horizontal:

$$
Q_{s}=F_{s} I_{g h}[\mathrm{~kW}]
$$

where

$F_{s}=$ solar gain factor

$I_{g h}=$ global horizontal solar incidence $\left(\mathrm{kW} / \mathrm{m}^{2}\right)$

The model uses five parameters:

$C_{a}=$ thermal capacity of the air in the zone, together with other fast-response elements $(\mathrm{kJ} / \mathrm{K})$

$C_{w}=$ lumped thermal capacitance of the structure $(\mathrm{kJ} / \mathrm{K})$

$K_{f}=$ fast conductance ascribed to ventilation, infiltration, and elements with little thermal capacitance, e.g., windows $(\mathrm{kW} / \mathrm{K})$

$K_{i}=$ conductance between the air and structure nodes $(\mathrm{kW} / \mathrm{K})$

$K_{O}=$ conductance between the structure node and the outside air $(\mathrm{kW} / \mathrm{K})$

While it is possible to estimate these parameters from physical data for the building, given the availability of monitoring data it was decided to obtain values for each of the three zones using a parameter identification technique.

Table 1 provides some basic information about the zones. The exhibition hall is the largest heated volume, which also has a high ceiling. Its exposed surface area to heated volume ratio $(0.324)$ is nearly $50 \%$ higher than that of the restaurant $(0.227)$. The exhibition hall also has the highest glazing-to-floor area ratio.

Monitoring data were available for the winter of 2001-2002 and were used in parameter estimation for the three zones. Externally, the outside air dry-bulb temperature and global solar radiation on the horizontal were logged; internally, the zone air temperature, supply air temperature, and duct air velocity readings enabled the heat input to the zone, as well as the zone air temperature, to be established. However, as the duct air velocity readings were found unreliable, it was decided to also identify the airflow rate to each zone in addition to the solar gain and casual gain

Table 1. Heated Zones in the Environment Centre

\begin{tabular}{cccc} 
& Exhibition & Classroom & Restaurant \\
\hline \hline Floor area $\left(\mathrm{m}^{2}\right)$ & 217.9 & 74.0 & 178.6 \\
Heated volume $\left(\mathrm{m}^{3}\right)$ & 1510.7 & 277.6 & 670.0 \\
Area of south-facing glazing $\left(\mathrm{m}^{2}\right)$ & 66.6 & 11.4 & 9.3 \\
Glazing to floor area ratio $(\%)$ & $36.1 \%$ & $18.8 \%$ & $8.4 \%$ \\
$\quad$ Exposed surface area to & 0.324 & 0.244 & 0.227 \\
\hline
\end{tabular}


factors. As a result, for each zone there are eight parameters $\left(C_{a}, C_{w}, K_{f}, K_{i}, K_{o}, M_{a}, F_{c}\right.$, and $\left.F_{s}\right)$ to be identified.

A constrained evolutionary strategy (Hanby et al. 2002) was used to find the values of the parameters that minimized the sum of the squares of the differences between the predicted and measured zone air temperatures. Data for March 2002 were selected for this purpose. The methodology was validated by first estimating the parameters for the zones from physical data then running the model to obtain a set of "observed" values for the zone air temperatures. The parameter identification process should then regenerate the values, which were assumed to generate the time-series data. Repeated runs of the evolutionary strategy confirmed that, in each case, the original parameters were found to be accurate within 5\% and that the zone temperatures were calculated to within $\pm 0.1^{\circ} \mathrm{C}$.

Parameter values identified, including the prediction error, for the heating period of 2001-2002 for the three zones are summarized in Table 2.

It was of interest to note that the model was insensitive to values of $C_{w}$ and $K_{i}$ in the region where their values are greater than the optimum. General agreement between the predicted zone air temperatures and those logged by the BEMS was obtained for all of the three zones, as illustrated by Figure 4. The root mean square and maximum of the prediction errors for each zone are listed in Table 2. Larger discrepancies (up to $2^{\circ} \mathrm{C}$ ), however, were observed in the restaurant area in some days. Detailed examination of the data suggested that several factors could contribute to this situation, including the difficulty of predicting casual gains and occupant behavior (e.g., opening the windows). Casual gains were estimated from the known staff occupancy and the admissions system, which quantified the number and frequency of visitors.

The variation of space air temperatures should be seen in the context of the temperature control. Output from a sensor in each of the three zones is fed to the BEMS, which calculates the mean value that is used to reset the air supply temperature, which is common to all zones. The prediction error in Table 2 and Figure 4 should be read in this context. In order to compare the performance of the existing BEMS control and the proposed optimal control strategies, the average space temperature is used hereafter, although each zone is modeled separately.

\section{BUILDING AND SYSTEM MODEL}

The physical components of the plant were grouped into two subsystems, air and water. The complete system model was divided into four modules, as shown in Figure 5.

Table 2. Optimized Zone Model Parameters

\begin{tabular}{cccccc}
\hline & & Exhibition & Classroom & Restaurant & Average \\
\hline \hline$C_{a}$ & $(\mathrm{~kJ} / \mathrm{K})$ & $5.74 \times 10^{4}$ & $2.81 \times 10^{4}$ & $7.76 \times 10^{4}$ & - \\
$C_{w}$ & $(\mathrm{~kJ} / \mathrm{K})$ & $8.51 \times 10^{4}$ & $1.62 \times 10^{5}$ & $3.63 \times 10^{6}$ & - \\
$K_{f}$ & $(\mathrm{~kW} / \mathrm{K})$ & 0.164 & 0.236 & 0.042 & - \\
$K_{i}$ & $(\mathrm{~kW} / \mathrm{K})$ & 5.423 & 3.845 & 0.411 & - \\
$K_{o}$ & $(\mathrm{~kW} / \mathrm{K})$ & 0.143 & 0.115 & 0.001 & - \\
$M_{a}$ & $(\mathrm{~kg} / \mathrm{s})$ & 0.641 & 0.750 & 0.774 & - \\
$F_{c}$ & $(-)$ & 0.85 & 4.80 & 2.07 & - \\
$F_{S}$ & $(-)$ & 15.06 & 15.10 & 8.72 & - \\
Error $_{R M S}\left({ }^{\circ} \mathrm{C}\right)$ & 0.3877 & 0.4601 & 0.6185 & 0.3862 \\
Error $_{M A X}\left({ }^{\circ} \mathrm{C}\right)$ & 1.0969 & 1.2891 & 1.9518 & 1.2176 \\
\hline \multicolumn{6}{r}{} \\
\end{tabular}



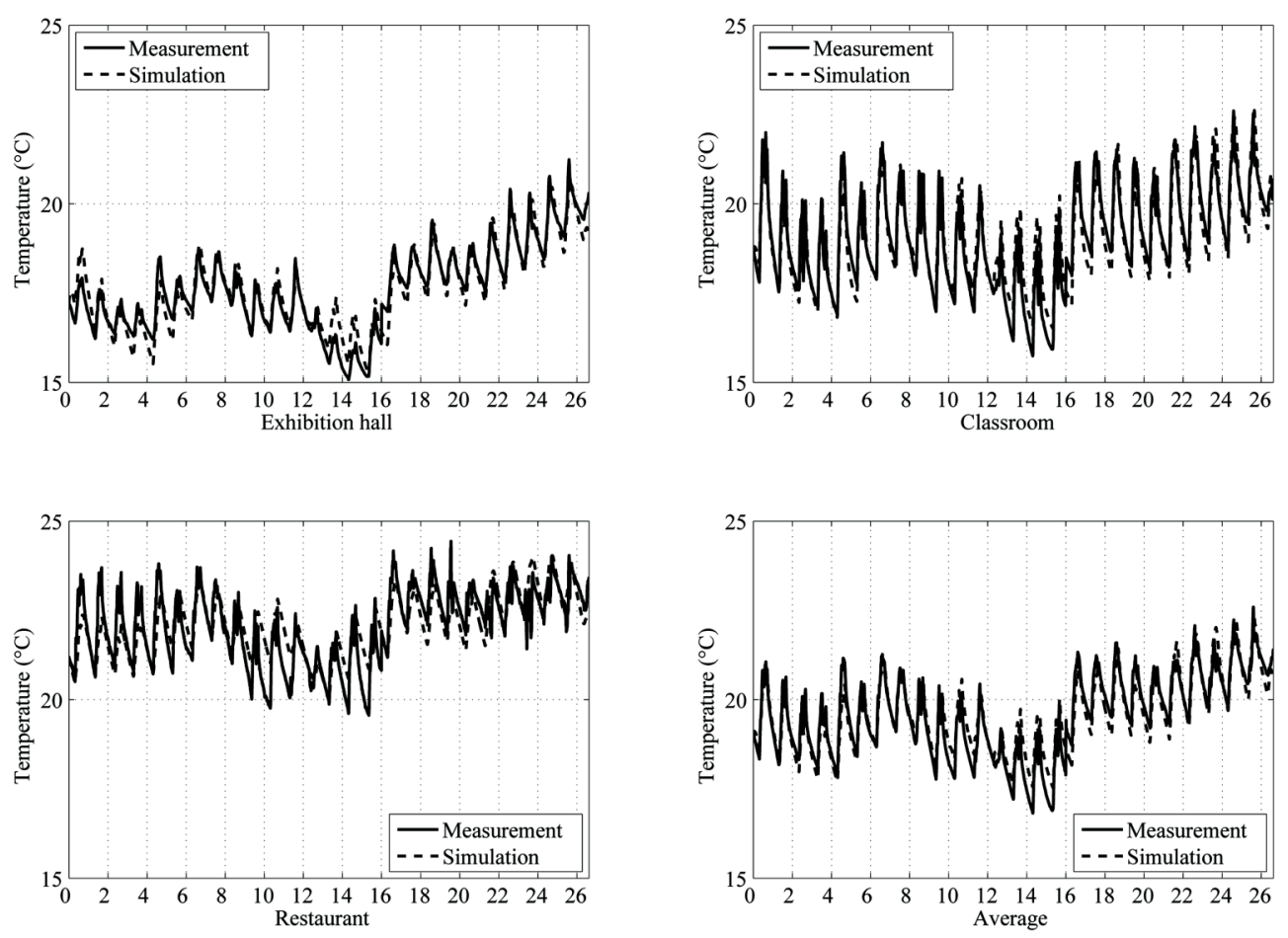

Figure 4. Observed temperatures compared with model outputs.

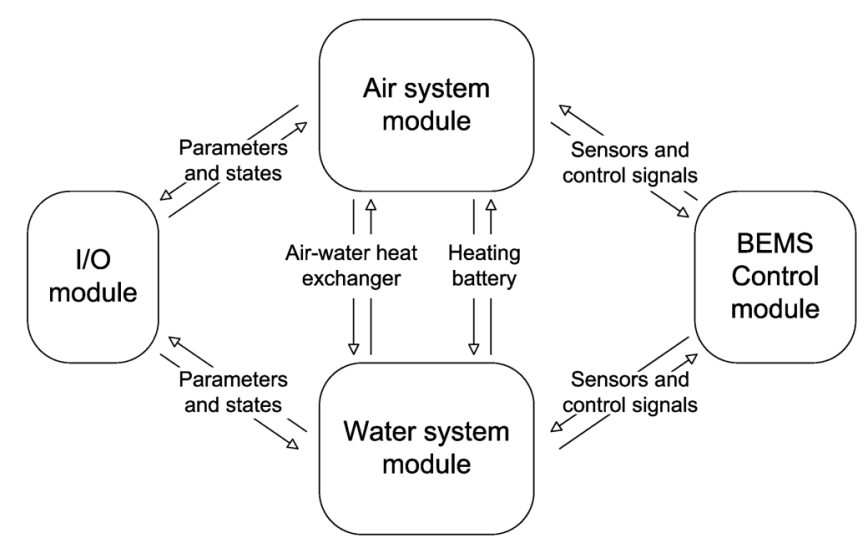

Figure 5. System modules and their interaction.

The air system module contains ventilated PV panels, solar air collectors, an air-to-air heat exchanger for heat recovery, an air-to-water heat exchanger for collecting heat from solar panels, a heating coil, fans, dampers, and the three zones. The water system module contains a boiler, an evacuated tube solar water collector, a stratified water storage tank, the domestic hot water storage tank and pumps, and valves. The water system module is coupled with the air system module via the air-water heat exchanger and the heating coil. The BEMS control module closely emulates the functions of the control system installed in the building. The controller 
takes values from the environment and the system and is connected to the motorized dampers, valves, fans, pumps, and the boiler. Finally, there is an I/O (meta-) module that sets simulation parameters, initializes state variables, and gathers outputs.

The models of the system components that have been selected and implemented in Simulink ${ }^{\circledR}$ include:

1. The models of the VPV/SA collector are adopted from Cartmell's (2004) study. These steady-state models have been specifically developed and validated for the components installed in the Brocks Hill Environment Centre.

2. The air-to-air cross-flow plate heat exchanger is based on the AIRHX model from the ASHRAE HVAC 2 Toolkit (Brandemuehl 1993).

3. The models for the air-to-water heat exchanger and the heating coil in the AHU are both based on the DRYCOIL model from HVAC 2 Toolkit (Brandemuehl 1993).

4. The models for the fans, dampers, pumps, valves, and the necessary flow mixers and diverters are derived from the simplified (pressure-independent) flow components in HVAC 2 Toolkit (Brandemuehl 1993).

5. The dual-fuel boiler was modeled in oil-fired mode only, using a load-related efficiency (Hanby and Li 1997). Although the unit is capable of firing on biomass, this has never been implemented and it is unlikely that this will happen in the near future. Biomass firing will be a subject of future work, as the dynamics of this mode are substantially different from oil- or gas-firing and would be expected to have a significant influence on system operation.

6. The model of the evacuated solar-water collector was developed using the manufacturer's efficiency curve (Thermomax 2006) coupled with first-order dynamic water temperature node.

7. The dynamic models for the active heat storage, including the stratified water tank (eight nodes) and the domestic hot water tank (fully mixed with internal heat exchanger), are implemented using the tank models described by Newton et al. (1995).

The system model contains a mixture of dynamic and steady-state component models. As the dynamics of building and plant components are combined, a stiff system of equations is produced. A modified order-2 Rosenbrock formula-based solver was used.

Figure 6 shows temperature profiles of the building and storage tanks without the boiler firing or mechanical ventilation in an intermediate season (April). Throughout the day, the average zone temperature was maintained above $20.0^{\circ} \mathrm{C}$. The average space temperature increased $0.5^{\circ} \mathrm{C}$ after 24 hours due to the high solar gain and the internal load. The diurnal fluctuation of the
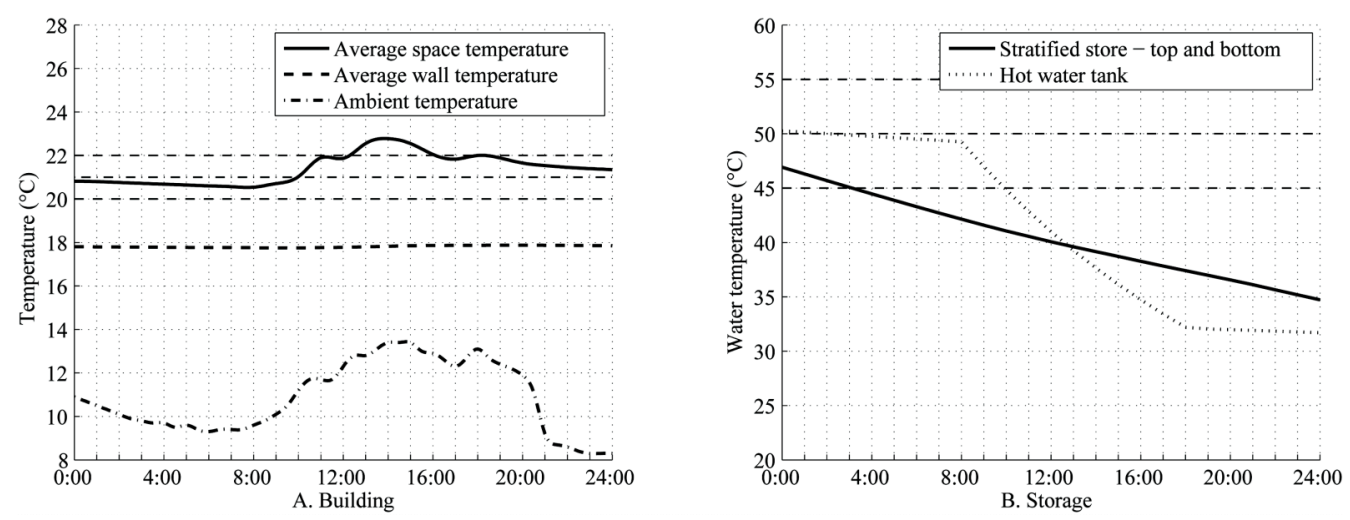

Figure 6. Temperature profiles of the building and storage tanks in passive mode. 
average temperature of the building envelope is minimal. In contrast, the temperature of the domestic hot water cylinder dropped from $50.0^{\circ} \mathrm{C}$ to about $32^{\circ} \mathrm{C}$ over the same period. In this case, water heating is required for charging the storage and hot water tanks, whereas (free) cooling is required to maintain the comfort in the occupied zones.

\section{BEMS CONTROL STRATEGIES}

The default control strategy implemented in the BEMS system was based on a set of predefined rules and setpoints devised by the design engineer for the building project. By coordinating the operation of the dampers and fans, four operational modes are available for the solar/air system:

- VPV preheating - when there is heating demand and there is useful heat from the VPV panels, the outside air is first directed into the VPV before being fed to the AHU.

- VPV storage - when there is no heating demand and there is useful heat from the VPV panels and also available capacity in the storage tank, the air in the VPV is circulated in a closed loop and the solar heat is collected and stored in the tank using the air-water heat exchanger.

- VPV venting - when there is excess heat in the VPV panels (temperature exceeding $80^{\circ} \mathrm{C}$ ) and there is neither heating demand nor available storage capacity, the VPV is actively vented to ambient.

- VPV bypass - for all other conditions, the VPV is bypassed and the outside air is directly supplied to the AHU.

During the heating season, the average space temperature is regulated by the operation of the AHU. The average space temperature (arithmetic mean of temperature readings of the three zones) is compared with the occupied setpoint at $21^{\circ} \mathrm{C}$ to determine the space heating demand. The desired supply temperature is subsequently calculated and used as the setpoint for the condition of supply air. A PI controller regulates the supply air condition in three steps. First, it checks the availability of preheating with the VPV panels and adjusts the mixture of preheated and bypassed outside air to the AHU. Second, it adjusts the face and bypass dampers for the heat-recovery unit. And, finally, it deploys the heating coil in the AHU to achieve the supply air setpoint. In summer, cooling demand is not handled by the BEMS, except that the night cooling mode is triggered when the average space temperature is higher than the occupied setpoint, as well as more than $2^{\circ} \mathrm{C}$ higher than the outside air temperature.

One simplification of the BEMS model is the removal of air quality control. The BEMS in the building is designed to activate the supply and extraction fans when $\mathrm{CO}_{2}$ content in the occupied space reaches a certain level and when there is heating demand. During the monitoring period, however, the fans are seldomly triggered by $\mathrm{CO}_{2}$ level due to generally low occupancy density in the building. Therefore, the $\mathrm{CO}_{2}$ level control is omitted from both the BEMS model and the developed optimal control model. This function is nevertheless necessary if the developed control strategy is to be implemented in the building.

The operation of the boiler is determined by the high-level temperature of the storage tank. The boiler and the associated pumps are only switched on when there is heating demand together with a high-level temperature in the tank lower than $45^{\circ} \mathrm{C}$. Once switched on, however, the boiler will keep running until the high-level temperature of the tank reaches $60^{\circ} \mathrm{C}$. The domestic hot water temperature is regulated by a PI controller that operates the water-heating pump and valve during the occupied hours.

The deployment of the evacuated tube collectors starts when the temperature in the manifold is $10^{\circ} \mathrm{C}$ higher than the low-level temperature of the stratified storage tank and stops when either the manifold temperature is equal to the low-level temperature or when the high-level temperature of the tank reaches $60^{\circ} \mathrm{C}$.

It is arguable that a control strategy with fixed control rules and setpoints would not be the most efficient solution in a changing environment. However, there are as yet no industry standard control schemes for innovative mechanical service systems such as these. This poses a 
problem as to the specification of a benchmark with which to compare any optimal control strategy. In these circumstances, the actual control strategy implemented was taken as the baseline against which proof of the concept of optimal control could be measured.

\section{OPTIMAL CONTROL STRATEGY}

With a functioning, calibrated model of the building and its systems in place, the next stage of the work was the implementation of an optimal control strategy. The overall approach is that during the unoccupied overnight period, an evolutionary optimization method is used to devise a supervisory control trajectory for the next day. This incorporates information relating to building use together with a short-term forecast for the following day's weather. The control trajectory will then be updated during the day using a faster optimization algorithm (such as a micro-genetic algorithm), which is economical in function evaluations, as the execution time of the complete model is the biggest challenge to eventual real-time application. In order to provide the fullest comparison with an arbitrary rule-based approach, no domain-specific knowledge was incorporated into the determination of the supervisory control.

In general, an optimization problem is to minimize/maximize the objectives that are subjected to a number of qualitative and quantitative constraints. The optimization problem for the optimal supervisory control strategy has been formulated as the constraint-satisfying minimization problem in Equations 7 and 8.

Minimize:

$$
J=\sum_{i=1}^{M} J_{i}=\sum_{i=1}^{M} f_{i}\left(X_{i}\right)
$$

subject to:

$$
a_{i, j} \leq h_{i, j}\left(X_{i}\right) \leq b_{i, j}
$$

where

$J_{i}=J_{1}, \ldots, J_{M}$

= energy consumption (fuel and electricity) during each of the $M$ time steps

$X_{i}=\left(x_{1}, \ldots, x_{N}\right) \in \mathfrak{R}^{N} \quad=$ the set of control signals, $N$ in total, for each time step

$h_{i, j}, i=1 \ldots M, j=1 \ldots K \quad=$ constraints for maintaining the comfort conditions in the controlled zones, the domestic hot water temperature, and the (frost and overheating) protections to the system

$a_{i, j}, b_{i, j}, i=1 \ldots M, j=1 \ldots K=$ lower and upper limit of each constraint value; in this case, the minimum and maximum temperature at each of the $K$ monitored positions

The objective of the control problem is to minimize the net external energy consumption of the system subject to the following constraints:

- Comfort conditions to be maintained in the occupied zones during the occupied hours, for example, by maintaining the temperature between $20^{\circ} \mathrm{C}$ and $22^{\circ} \mathrm{C}$.

- Temperature of the domestic hot water service to be maintained at $50^{\circ} \mathrm{C} \pm 5^{\circ} \mathrm{C}$ during the occupied hours.

- The maximum temperature in the storage tank should not exceed $85^{\circ} \mathrm{C}$.

- The temperature of any part of the water system should be maintained between $5^{\circ} \mathrm{C}$ and $95^{\circ} \mathrm{C}$.

The major control signals in the system are summarized in Table 3.

The overnight identification of an optimal control schedule for the following 24 hours will require 24 sets of control signals to be optimized in advance. As each set of control signals contains 13 individual commands to the actuators in the system, in total there are 312 commands 
Table 3. Control Signal Definitions

\begin{tabular}{cccc}
\hline ID & Control Signals & Type (Bits) & Range \\
\hline \hline 1 & Hot water heater pump/valve (P4/MV2) & $0 / 1(1)$ & {$[0,1]$} \\
2 & Boiler ON/OFF/boiler circulation pump (P3) & $0 / 1(1)$ & {$[0,1]$} \\
3 & Evacuated tubes collector circulation pump (P2) & $0 / 1(1)$ & {$[0,1]$} \\
4 & VPV/SA air-water heat exchanger pump (P1) & $0 / 1(1)$ & {$[0,1]$} \\
5 & Supply fan ON/OFF & $0 / 1(1)$ & {$[0,1]$} \\
6 & VPV/SA preheating damper/outside air damper $(\overline{\mathrm{D} 2} / \overline{\mathrm{D} 3})$ & $\%(4)$ & {$[0,1.0]$} \\
7 & AHU heating unit valve (MVAHU) & $\%(4)$ & {$[0,1.0]$} \\
8 & AHU heating unit pump (P5) & $0 / 1(1)$ & {$[0,1]$} \\
9 & Heat recovery exchanger bypass/face damper $\left(D_{b y p a s s} / \overline{D_{f a c e}}\right)$ & $\%(4)$ & {$[0,1.0]$} \\
10 & VPV/SA inlet damper (D1) & $0 / 1(1)$ & {$[0,1]$} \\
11 & VPV/SA recirculation fan ON/OFF & $0 / 1(1)$ & {$[0,1]$} \\
12 & VPV/SA recirculation damper (D4) & $0 / 1(1)$ & {$[0,1]$} \\
13 & VPV/SA heat rejection damper (D5) & $0 / 1(1)$ & {$[0,1]$} \\
\hline
\end{tabular}

(variables) to be optimized. This represents a significant search space, and the principal challenge for the optimization process is that for each function evaluation the complete system model has to be run over 24 hours of simulated time. Hence, the key attribute of the search method is not the execution of the search algorithm but economy in requiring function evaluations.

An evolutionary algorithm was identified as the most appropriate approach to this problem. These methods work with a population of solutions so that when the search is terminated there will probably be a number of individuals that could represent near-optimal solutions. When the search is updated during the course of the day, existing members of the population will provide a more effective starting point than randomly seeding the individuals within the bounds of each variable. The general scheme of the linking of the optimization algorithm with the dynamic system model is shown in Figure 7. In the example solution presented here, a genetic algorithm (Goldberg 1989) was implemented with a population size of 20 individual solutions in each generation. A larger population will, among other things, reduce the likelihood of the search terminating at false optima; however, the execution time is dominated by calls to the system model, which will increase linearly with population size. Preliminary numerical experiments indicated that a population of 20 was a reasonable compromise. Constraint violations were quantified by integration of the control errors (in the case of setpoint variables), and the method of stochastic ranking (Runnarsson and Yao 2000) was used to enable the search to continue through infeasible regions. The optimization was run for an arbitrarily fixed time of 500 generations, which gave a computing time of 24 hours on a $3 \mathrm{GHz} \mathrm{PC}$.

\section{EXPERIMENTAL RESULTS}

Three days of the recorded weather data from 2002 were used to emulate the operation of the control strategies for the winter, intermediate, and summer seasons. Days with clear skies were deliberately chosen in order to demonstrate the operation of the solar collectors. The weather conditions of the three days are summarized in Table 4. Since the global horizontal solar radiation data record was incomplete for the three days, solar irradiance measurement taken by the panel-mounted pyranometers is displayed. The occupied hours are 8:00 to 18:00. 


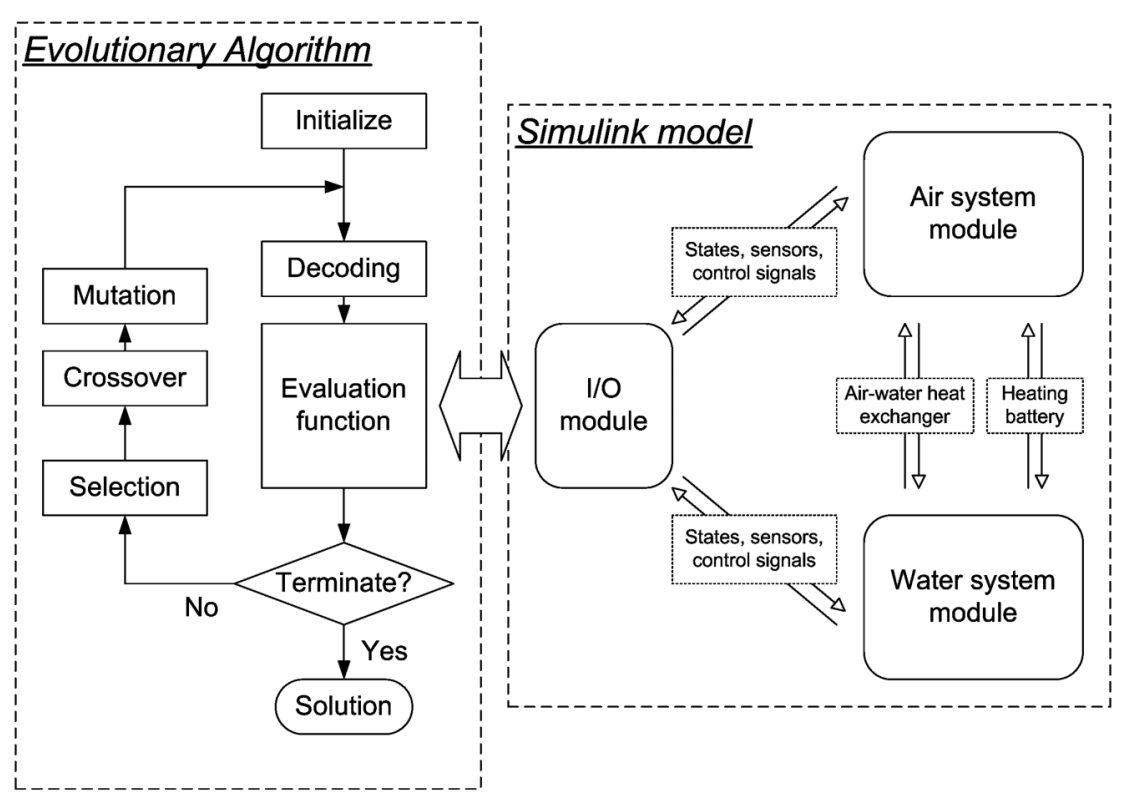

Figure 7. Model-based optimal control with evolutionary algorithm.

Table 4. Weather Conditions of Three Test Days

\begin{tabular}{cccc}
\hline & $\begin{array}{c}\text { Winter } \\
\text { (1 Jan 2002) }\end{array}$ & $\begin{array}{c}\text { Spring } \\
\text { (1 Apr 2002) }\end{array}$ & $\begin{array}{c}\text { Summer } \\
\text { (26 Jul 2002) }\end{array}$ \\
\hline \hline Weather & Clear & Clear & Clear \\
Maximum temperature & $-0.1^{\circ} \mathrm{C}$ & $13.4^{\circ} \mathrm{C}$ & $26.2^{\circ} \mathrm{C}$ \\
Minimum temperature & $-6.6^{\circ} \mathrm{C}$ & $8.3^{\circ} \mathrm{C}$ & $16.2^{\circ} \mathrm{C}$ \\
Sunrise time & $08: 15$ & $05: 39$ & $04: 14$ \\
Sunset time & $16: 00$ & $18: 38$ & $20: 06$ \\
Maximum solar irradiance on PV & $604.9 \mathrm{~W} / \mathrm{m}^{2}$ & $1018.5 \mathrm{~W} / \mathrm{m}^{2}$ & $798.0 \mathrm{~W} / \mathrm{m}^{2}$ \\
Maximum solar irradiance on evacuated tubes & $769.5 \mathrm{~W} / \mathrm{m}^{2}$ & $997.9 \mathrm{~W} / \mathrm{m}^{2}$ & $739.1 \mathrm{~W} / \mathrm{m}^{2}$ \\
\hline
\end{tabular}

To provide a benchmark, the original BEMS control strategy was modeled first. Recorded weather data were used to compare both control systems, although when used in predictive mode the optimal control will need short-term forecasts for air temperature and solar radiation. Since 24-hour simulation for each season was a short period of time to analyze the performance of a dynamic building system, special care was taken in choosing the initial states of the system as well as controlling the final states after the simulation period.

In order to decide the initial states of the system for each test day, the system model with the BEMS control strategy was simulated for 21 days of repeated weather data. This ensured the system with BEMS control converged to a steady cycle in which, for each day, the final state at 24:00 equals the initial state at 0:00, and, therefore, the storage capacity in the system can be ignored. The exception was with the summer day, where the operational cycle would not con- 
verge due to the lack of cooling capacity. In this case, weather records for July 2002 were used to perform a system simulation for 25 days to determine the initial states for the test day.

Extra constraints were added to the optimal control strategy. First, the constraint on average space temperature reads that the difference between the average space temperature at 0:00 and 24:00 be less than $0.1^{\circ} \mathrm{C}$. Since the daily fluctuation of the average wall temperature of the building is minimal due to the heavy structure, it is not considered. The second constraint is that the temperatures of the water storage tanks at 24:00 be higher or equal to those at 0:00. Assuming that overcharging the storage tanks would cost energy (instead of save energy), it is a conservative measure to ensure that the optimal control does not save energy by cutting the storage level.

Figures 8, 9, and 10 show a comparison of the BEMS control and the optimal control on a winter day. The 24-hour profile of the average space temperature and the water temperatures are illustrated in Figure 8. For the BEMS control, the average space temperature is marginally lower than $20^{\circ} \mathrm{C}$ during the morning hours between 8:00 and 11:00, despite the fact that heating was started at 5:00. In the case of optimal control, the boiler started at 5:00, whereas space heating started at 7:00. The desired space temperature $\left(20^{\circ} \mathrm{C} \sim 22^{\circ} \mathrm{C}\right)$ is achieved before 9:00 and maintained throughout the occupied hours. For the domestic hot water temperature, which should be maintained between $45^{\circ} \mathrm{C}$ and $55^{\circ} \mathrm{C}$, the profiles under the two control strategies are quite different. With the BEMS control, the hot water temperature dropped below $45^{\circ} \mathrm{C}$ between 9:00 and 12:00 due to the low storage level in the thermal storage tank at the start of the day. In contrast, the hot water was overheated (over $55^{\circ} \mathrm{C}$ ) at 8:00 under the optimal control and subsequently fluctuated within the boundaries throughout the day.
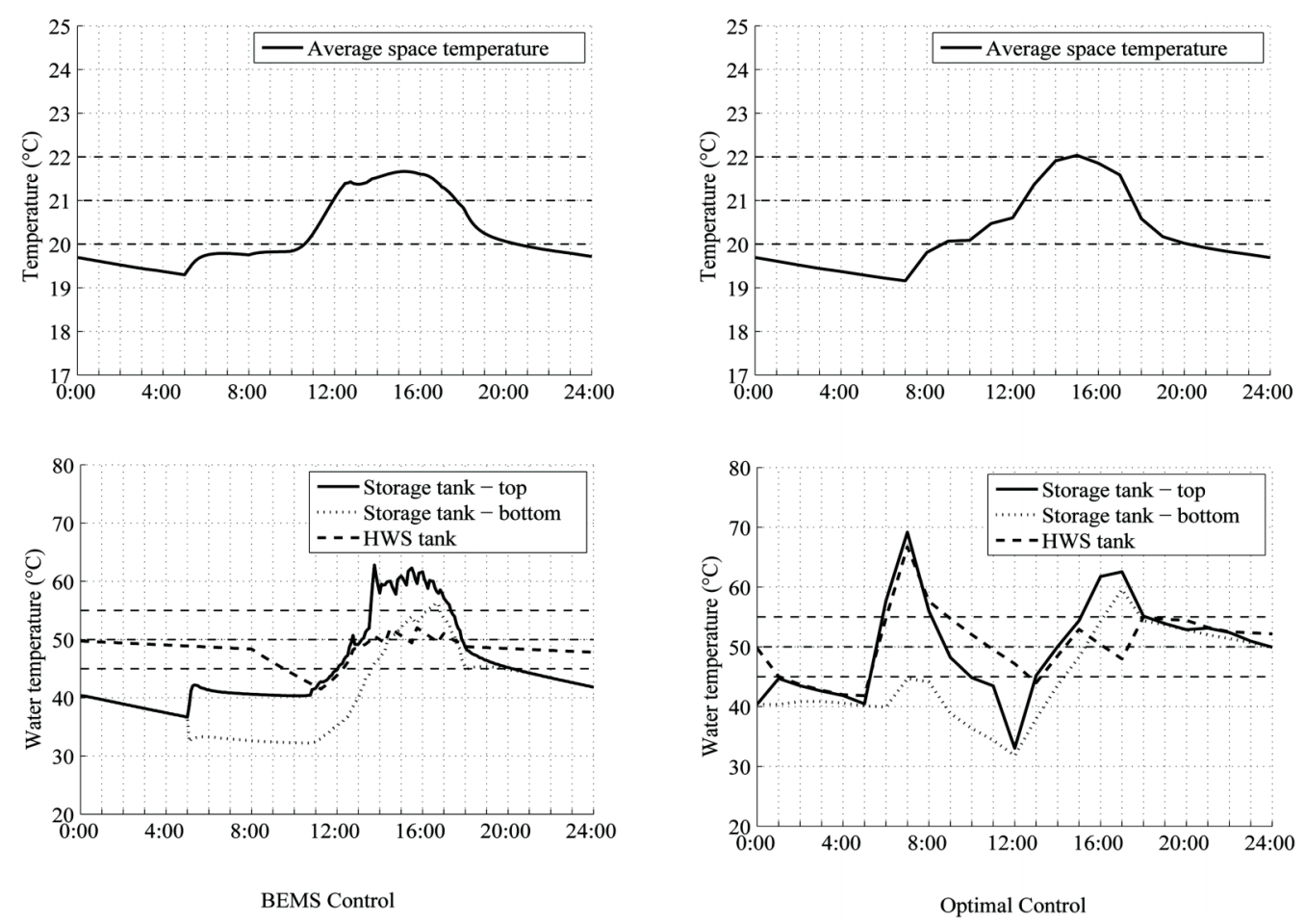

Figure 8. Comparison of system temperatures (1 January 2002). 
Figure 9 shows the control sequences that regulate the operation of the system. The stochastic nature of the optimization algorithm, namely, the genetic algorithm, is clearly seen. One clear difference between the BEMS control signals and the optimal control signals is the operational period of the supply fan. Under BEMS control, the supply fan was operated for 13 hours, compared to 7 hours in the case of the optimal control. Since it is only possible to provide heating by using ventilation and the Brocks Hill Environment Centre system has a fixed 100\% outside air ratio, the outside air preheating is the major part of the heating load on a winter day. The BEMS control strategy has been programmed to activate ventilation in the presence of heating demand. On a cold day such as the example, when the actual heating load exceeds the capacity of the heating system, reducing outside air load is the only way to keep the building warm. This strategy, which was not present in the rule base of the BEMS control, has been recognized by the optimal control. As a result, the reduction of the supply fan operation minimizes the overall heating load and saves electricity. On the other hand, reduced ventilation may have an impact on air quality in the building, despite the fact that the present occupancy density is low. It is preferable to incorporate an air quality model for the optimal control in the future to maintain sufficient fresh air supply.

The operation of the hot water heating pump (P4) and valve (MV2) under BEMS and optimal control are worth noticing. Under BEMS control, the P4 and MV2 were deployed only to maintain the setpoint during the occupied hours. Under optimal control, however, P4 and MV2 were enabled before the start of occupation. This effectively combined the capacities of both tanks to store heat and to discharge it when heating starts. As a result, more heating energy was available for delivery at 7:00 and the desired space temperature was achieved in a short period of time,
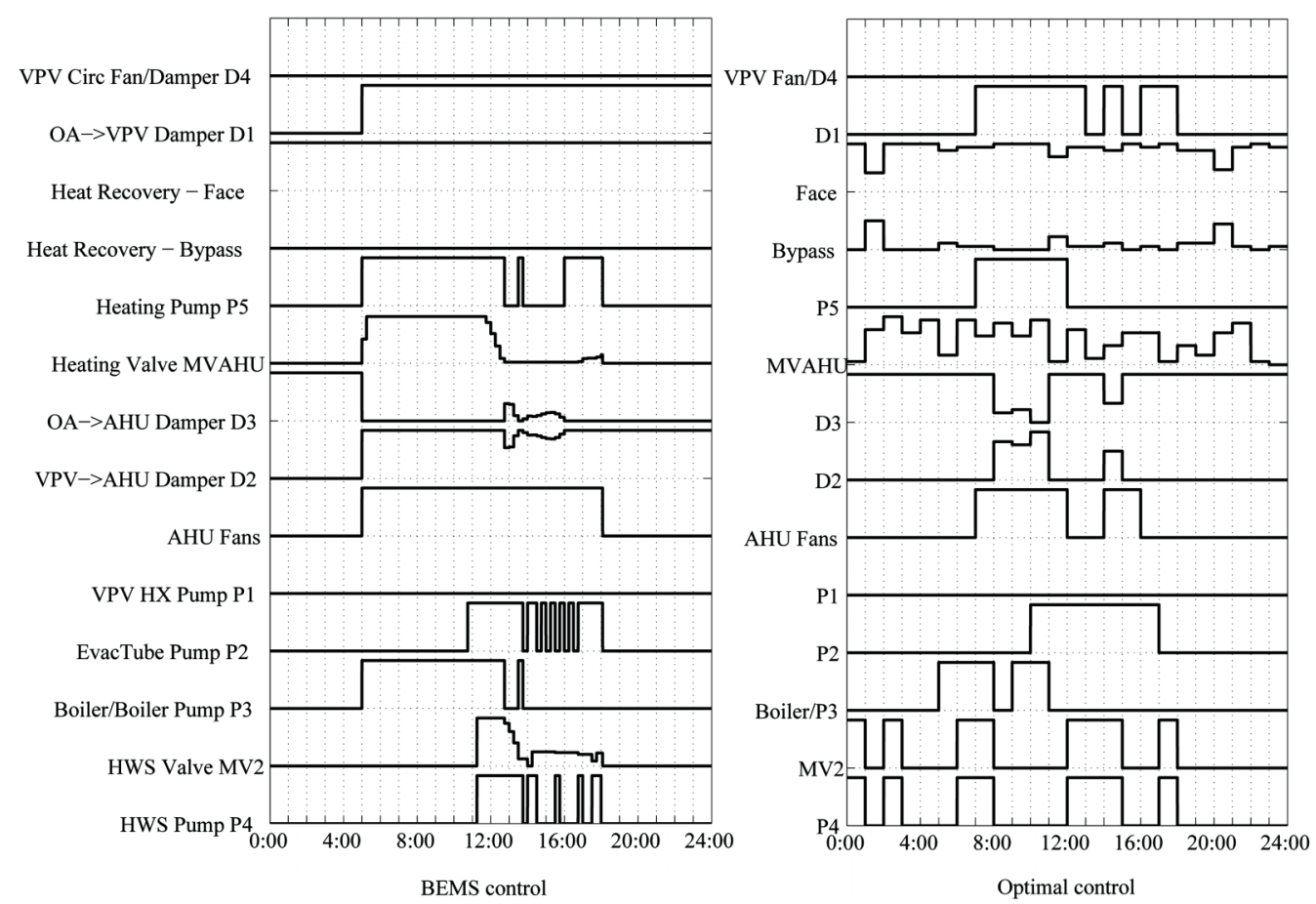

Figure 9. Control sequences (January 1, 2002). 
which consequently reduced the overall outside air load. It might be noted that this would be an operational mode that the original designer had not envisaged.

Figure 10 summarizes the fuel and electricity consumption as well as the solar energy collection. The system with optimal control consumed less energy due to the shorter operation time of the boiler (five vs. eight hours). It collected less solar energy as well, despite the fact that the storage levels of the tanks were higher after 24-hour operation. This suggests that solar energy collection itself is not a good objective function for optimal control.

During the test day in the intermediate season, the domestic hot water temperature was well controlled within the error limit, around $50^{\circ} \mathrm{C}$ throughout the occupied hours in both cases. The average space temperature was maintained between $20^{\circ} \mathrm{C}$ and $22^{\circ} \mathrm{C}$, too; except for the optimal control, slight overheating occurred at 13:00 (see Figure 11). Figure 12 shows the control sequences in these cases. With BEMS control, space heating was started 60 minutes before the start of occupation. The boiler was fired for about two hours in the morning to charge the storage tank, which subsequently regulated the hot water temperature. In the case of optimal control, the boiler was fired for a short time after midnight. Analysis showed this was a result of the large (60 minutes) time step used for the overnight optimization. Although it is interesting that such a solution occurred, running the boiler for 60 minutes will overcharge the storage tank, which will subsequently overheat the hot water. This situation could be avoided in the future by implementing a finer control time step or possibly local loop control.

Figure 13 shows the energy consumption and solar collection of the building system under the BEMS and optimal control strategies. For BEMS control, which has a fixed setpoint of $21^{\circ} \mathrm{C}$ for the average space temperature, solar energy collected by the ventilated PV panels was used to preheat the outside air in early morning in addition to the deployment of the heating coil. For optimal control, however, both the boiler and solar collector output were used for maintaining storage level and water heating. As a result, the overall load to the system was lower in the case of optimal control.
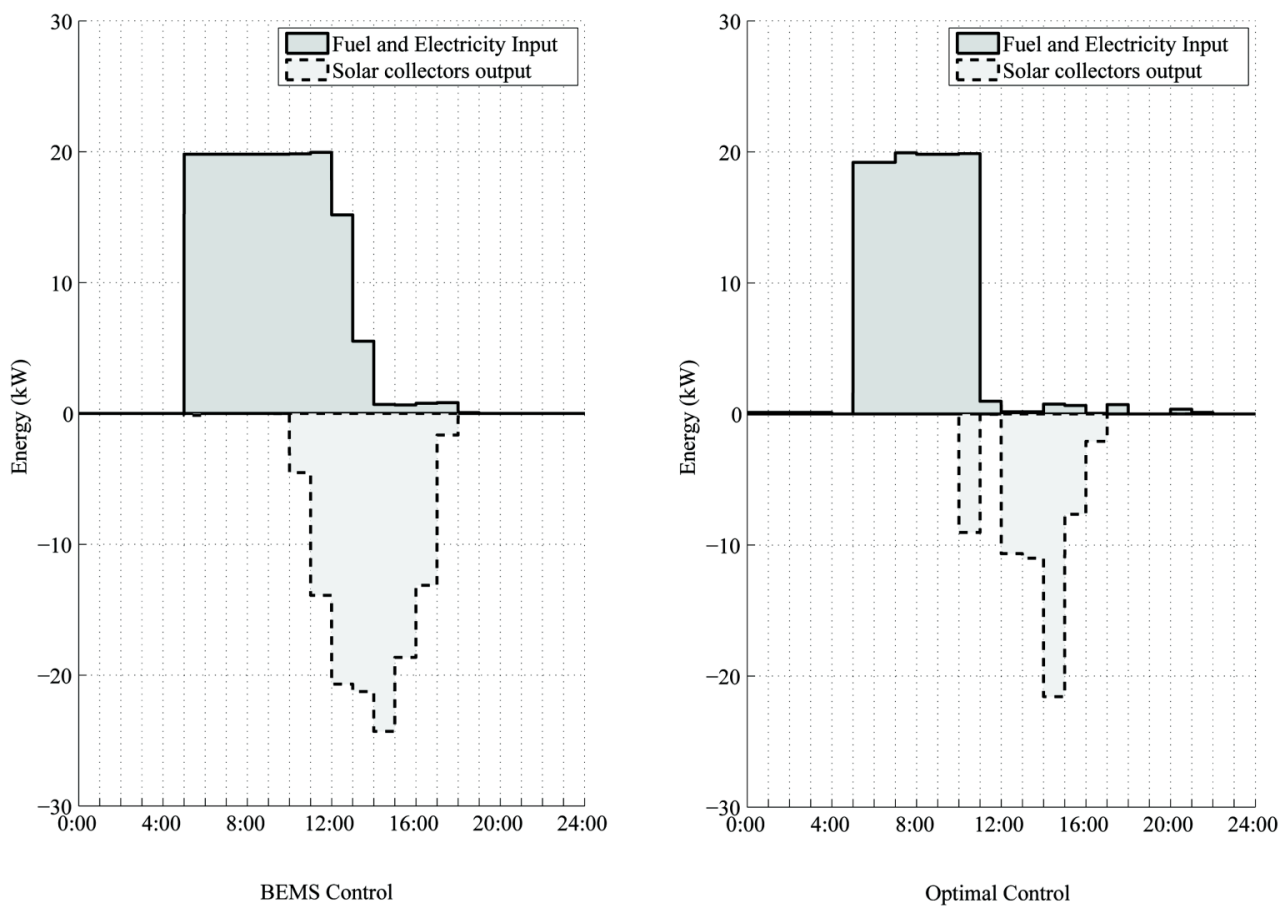

Figure 10. Energy consumption and solar collector output (January 1, 2002) (NB solar energy is shown as negative for clarity). 

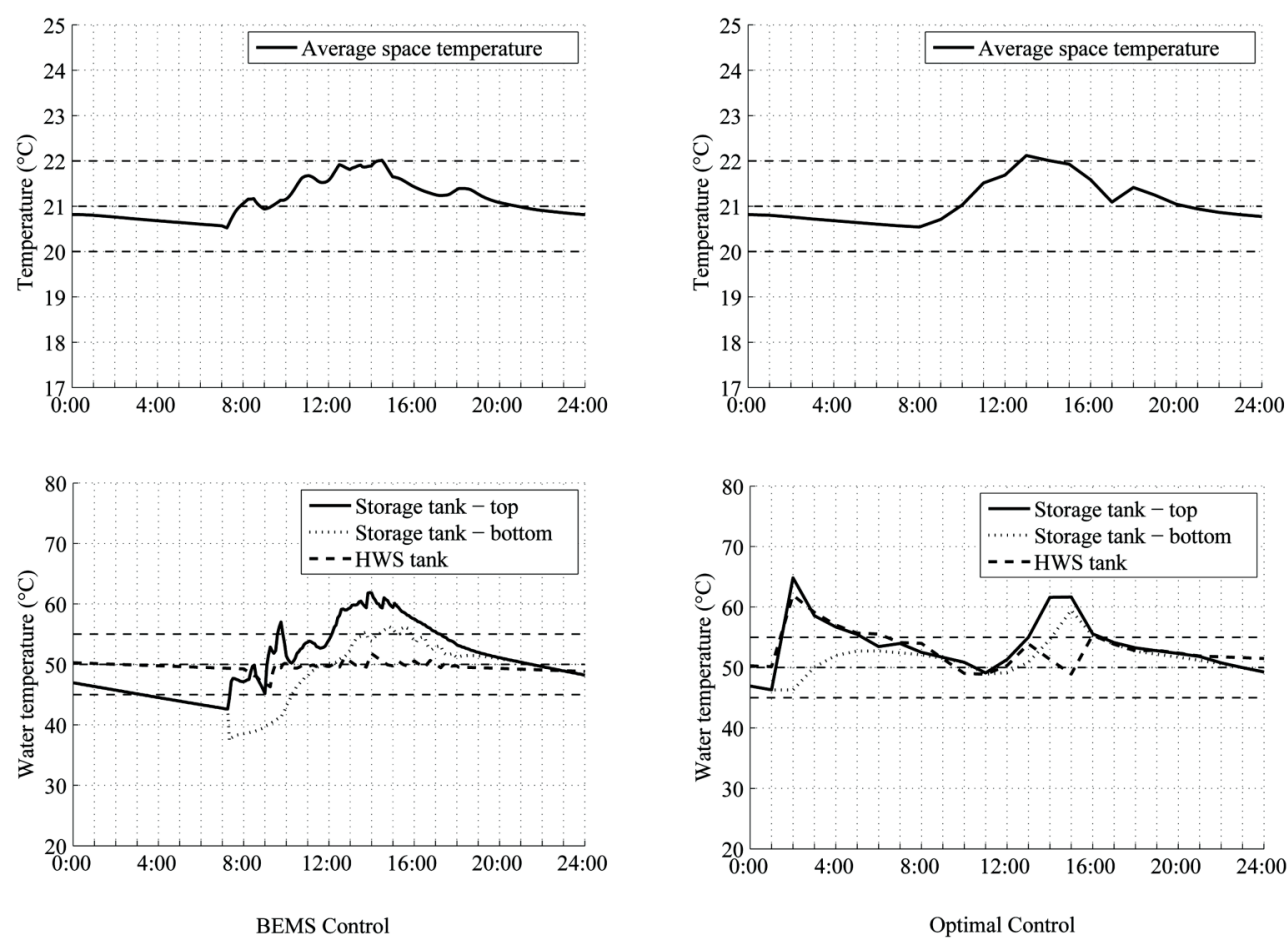

Figure 11. Comparison of system temperatures (April 1, 2002).
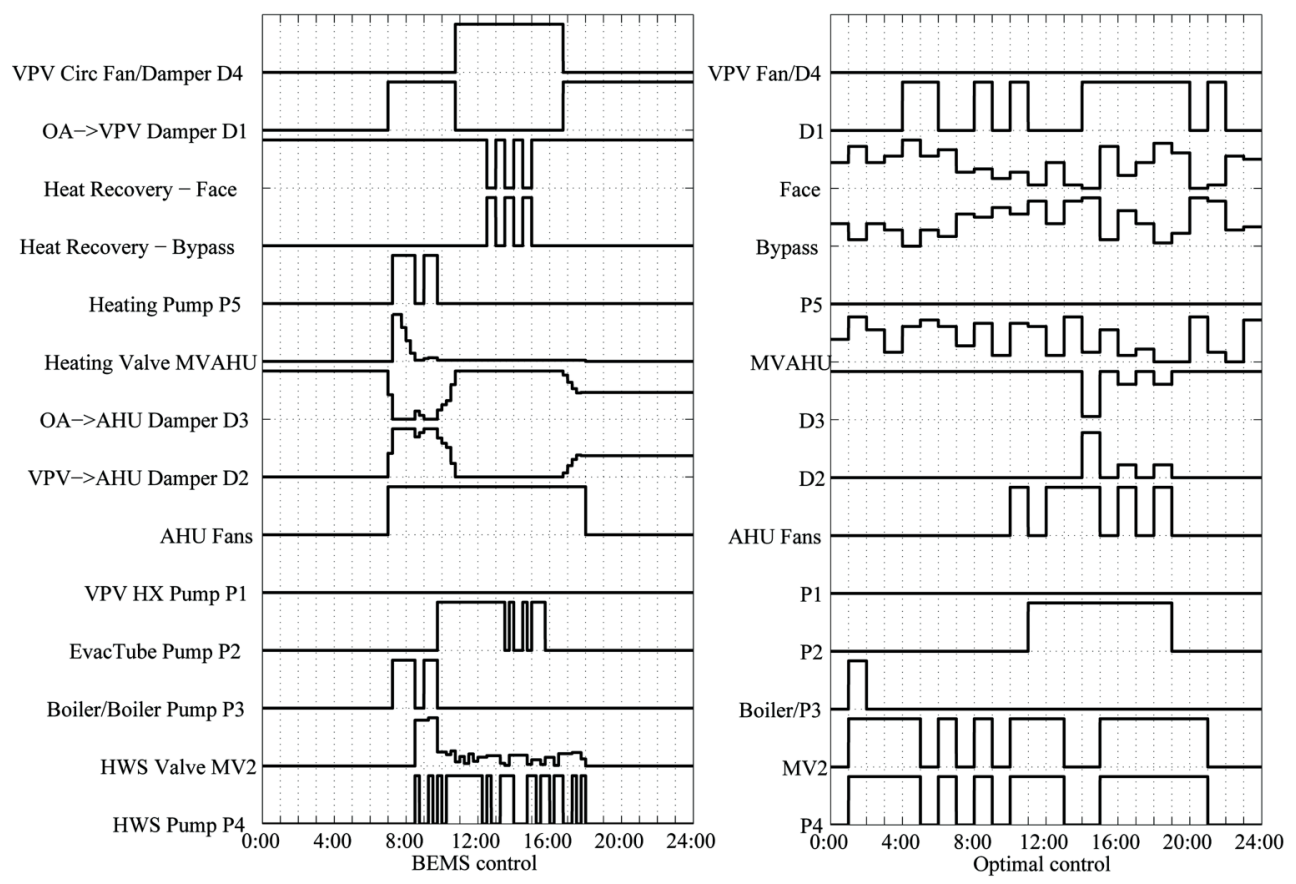

Figure 12. Control sequences (April 1, 2002). 

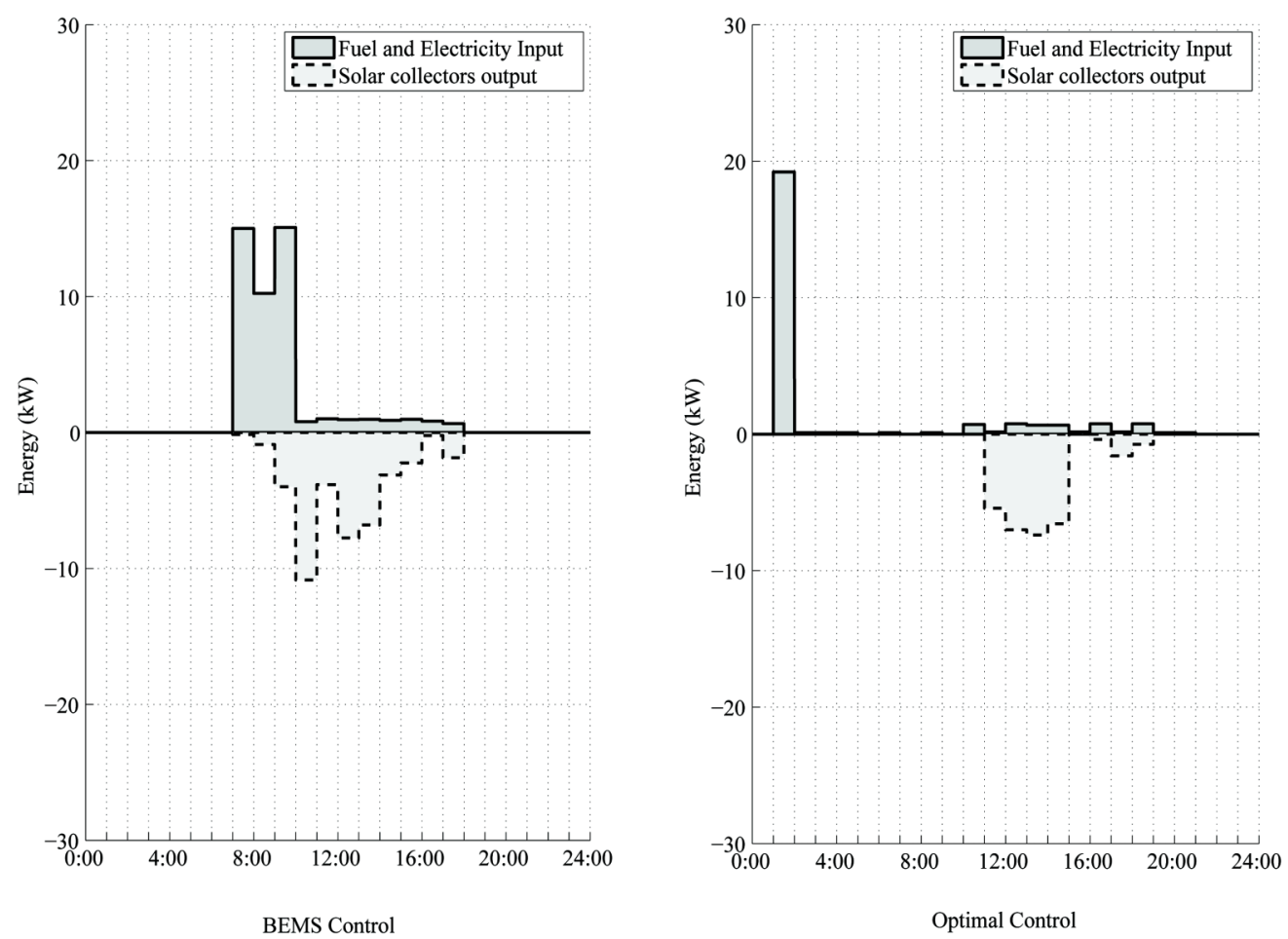

Figure 13. Energy consumption and solar collector output (April 1, 2002).

Figures 14, 15, and 16 illustrate the operation of the system on a summer day under both BEMS and optimal control. The optimal control strategy successfully identified the "night-cooling" mode without any predefined knowledge of this strategy. It also disabled ventilation when the ambient temperature was higher than the average space temperature during the day.

However, the comfort level achieved with optimal control is inferior to that achieved with BEMS control. The hot water temperature exceeded the upper limit of $55^{\circ} \mathrm{C}$ during the last occupied hour, too. Considering also that the evacuated-tube solar collector pump (P2) was operated at 21:00 for no obvious reason, the global optimal control sequence has not been identified in this case.

Table 5 summarizes the energy consumption and solar collection figures for the three test days.

These results suggest that a significant improvement in system performance could be obtained during "challenging" periods of operation when the building requires heating but when there is some potential for an active solar contribution. For a modest increase in fan energy, a significant increase in the performance of the VPV/SA panel array is obtained compared to the existing operation in four arbitrarily designated modes. An increase in the energy obtained from the evacuated tube solar hot water collectors suggests that the original rule for switching on the circulating pump was suboptimal.

The increased contribution from the solar panels, combined with more effective use of the active and passive thermal storage, has cut down the boiler firing by over half while maintaining acceptable zone temperatures and hot water supply availability. At present, boiler firing represents an external input of energy as it is restricted to oil firing. The future change to on-site bio- 

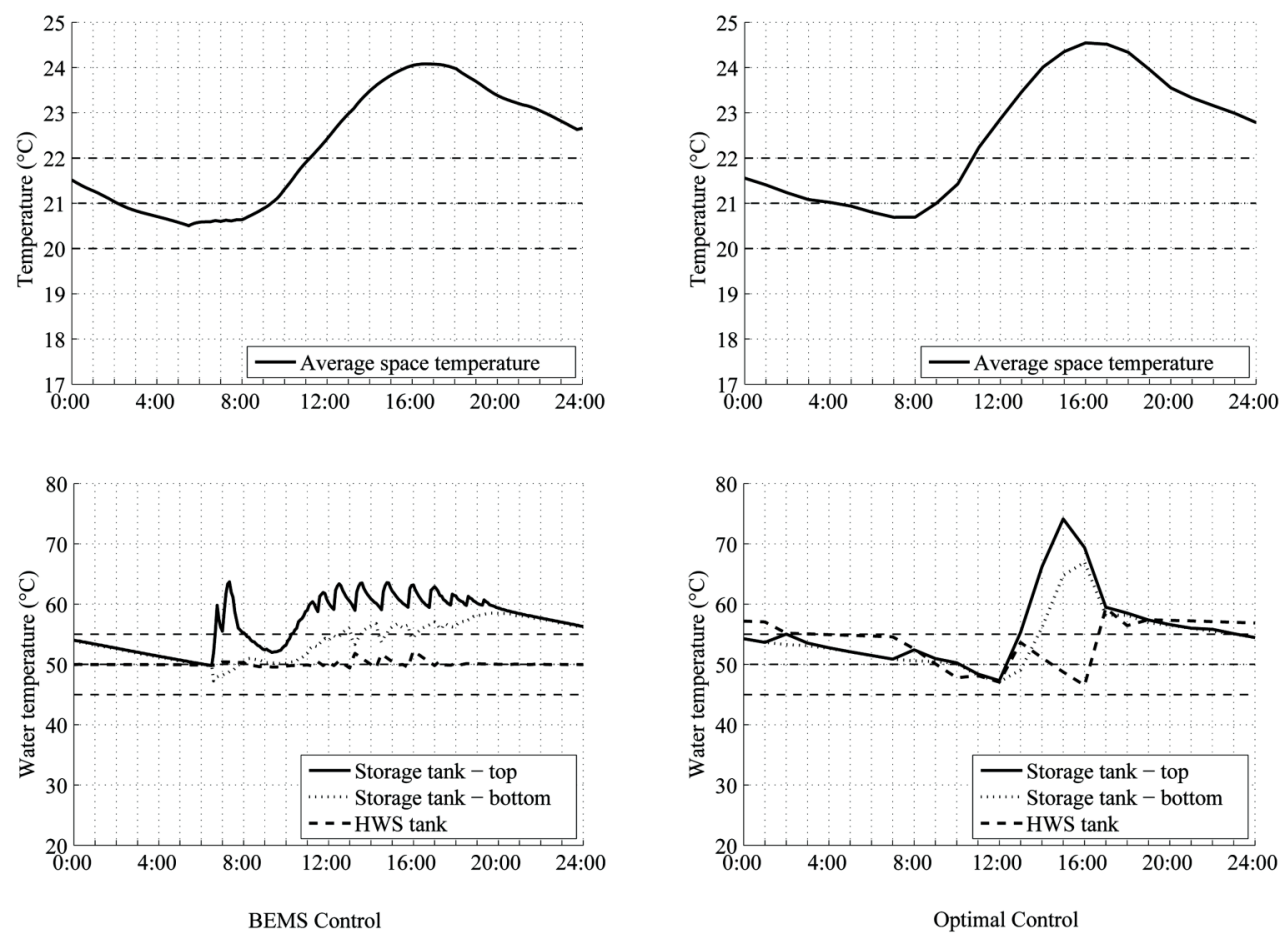

Figure 14. Comparison of system temperatures (July 26, 2002).

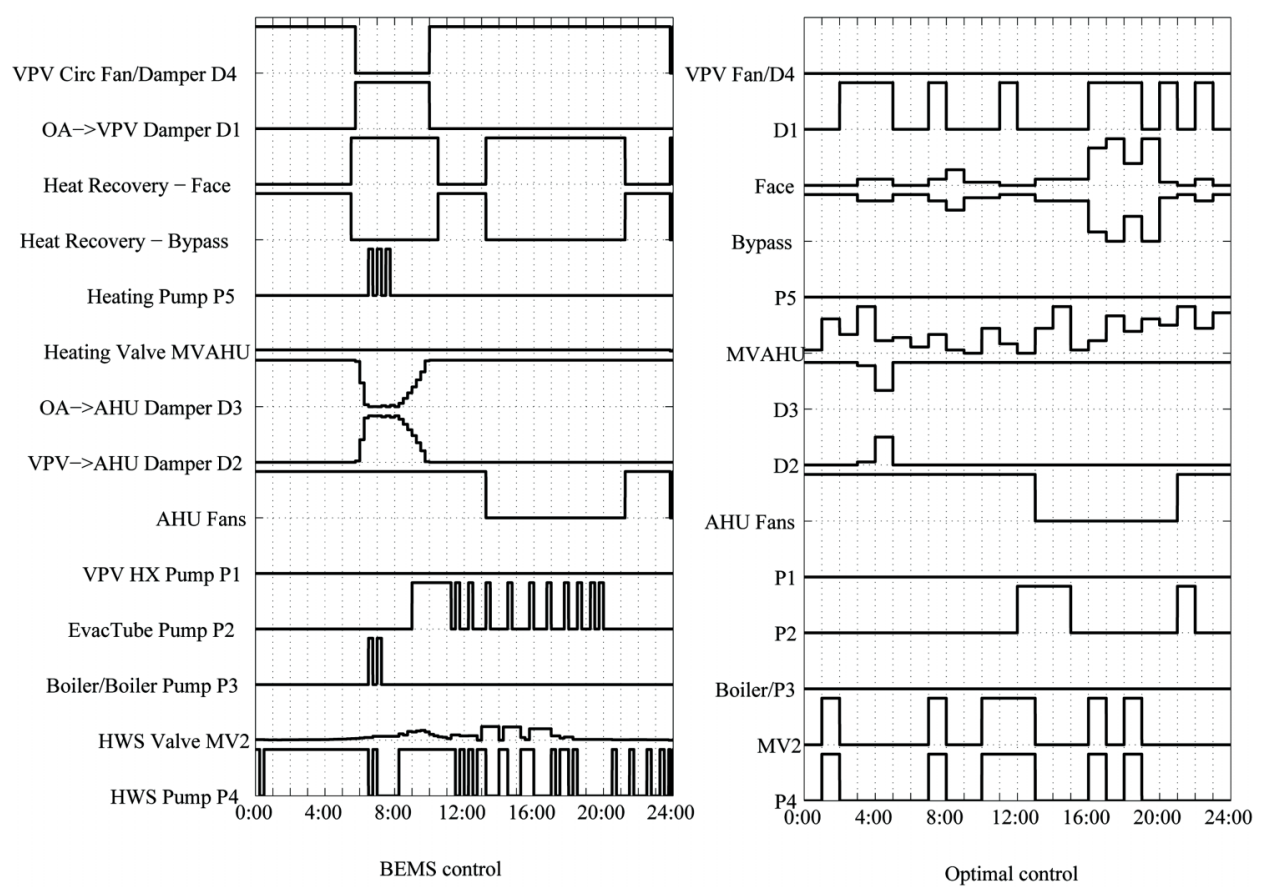

Figure 15. Control sequences (July 26, 2002). 

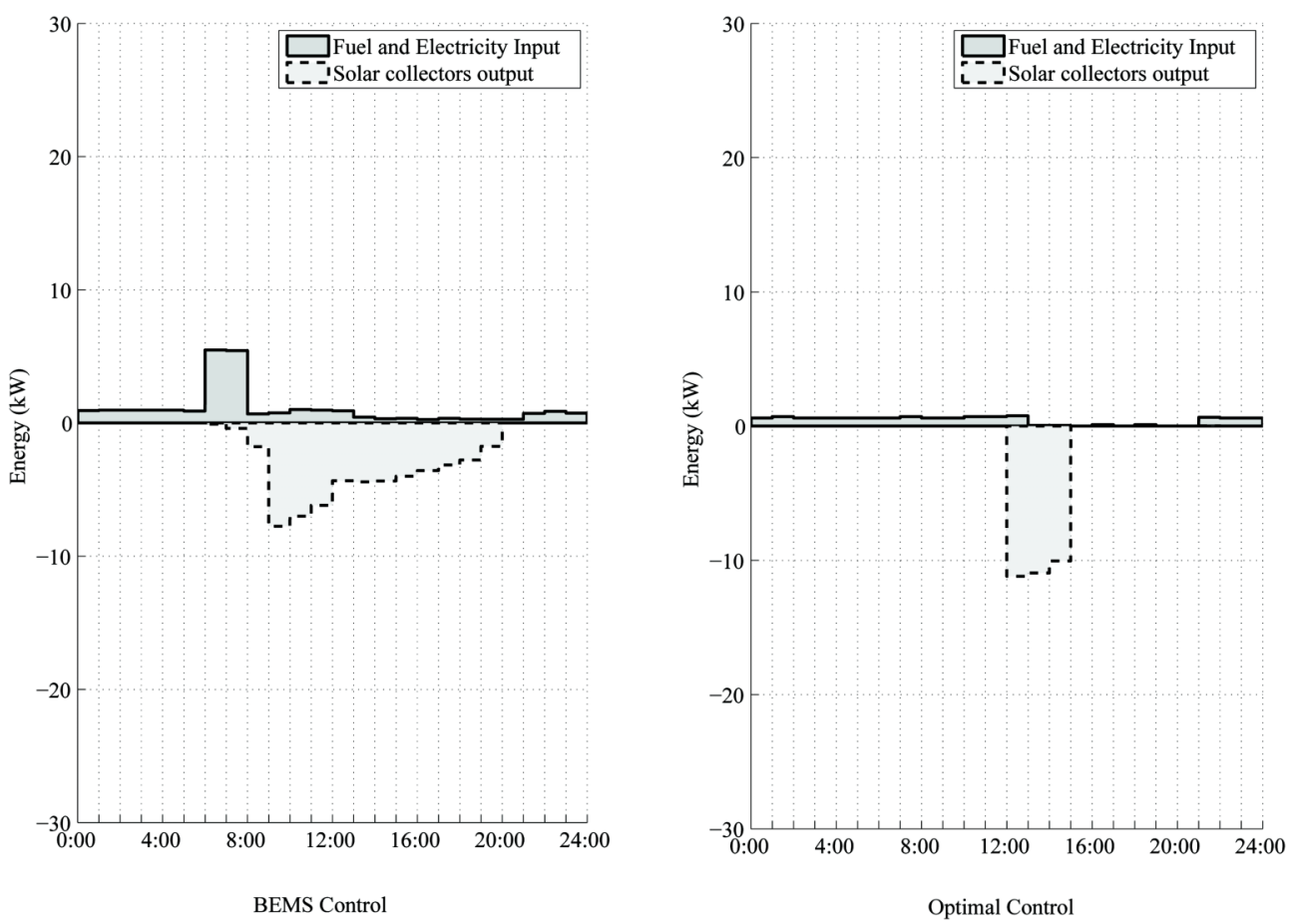

Figure 16. Energy consumption and solar collector output (July 26, 2002).

mass (wood) firing will present an additional modeling difficulty, as the dynamics of starting up and refueling such a device will need to be adequately represented.

The benchmark used in this work, namely, the control schedule implemented to the designer's principles, has no fundamental validity. For example, the temperature difference used to pump water through the evacuated tube collectors $\left(10^{\circ} \mathrm{C}\right)$ may well be questionable, as would, for example, the settings used for determining the mode of operation of the ventilated PV array. There is also no reservoir of practical experience (at least not in the UK) available to HVAC engineers to form a basis for the design of control systems that incorporate novel components combined with active and passive thermal storage.

Our experience within this project has highlighted the difficulty of devising a supervisory control scheme of this complexity and also in carrying out effective commissioning when the systems are so weather-dependent. The eventual implementation of model-based control could not only improve the energy efficiency of systems such as this but also have considerable benefits in commissioning, recommissioning, and fault detection and diagnosis.

\section{CONCLUSIONS AND FUTURE POTENTIAL}

The potential for optimal supervisory control of renewable energy systems in buildings has been investigated by the development of a calibrated system model for a low-energy public building that incorporates solar air and water heating, a ventilated photovoltaic array, a biomass boiler, and active and passive thermal storage. The modular structure enabled a supervisory control system to be integrated into the overall simulation. This model was combined with a modular evolutionary algorithm to facilitate the identification of optimal or near-optimal control strategies. 
Table 5. Comparison of Energy Consumption of the System under Alternate Control Strategies

\begin{tabular}{|c|c|c|c|c|}
\hline & & $\begin{array}{l}\text { BEMS } \\
\text { Control }\end{array}$ & $\begin{array}{l}\text { Optimal } \\
\text { Control }\end{array}$ & Savings \\
\hline Winter & Fans and pumps (kWh) & 10.5 & 8.2 & \\
\hline \multirow[t]{5}{*}{ (January 1,2002 ) } & Boiler input (kWh) & 152.0 & 114.0 & \\
\hline & Total consumption $(\mathrm{kWh})$ & 162.5 & 122.2 & $-24.8 \%$ \\
\hline & EvacTube output (kWh) & 42.5 & 47.5 & \\
\hline & VPV/SA output (kWh) & 64.7 & 14.2 & \\
\hline & Total solar collection ( $\mathrm{kWh}$ ) & 107.2 & 61.7 & $-42.4 \%$ \\
\hline Spring & Fans and pumps (kWh) & 9.4 & 5.7 & \\
\hline \multirow[t]{5}{*}{ (April 1, 2002) } & Boiler input (kWh) & 38.0 & 19.0 & \\
\hline & Total consumption $(\mathrm{kWh})$ & 47.4 & 24.7 & $-47.8 \%$ \\
\hline & EvacTube output (kWh) & 25.6 & 24.9 & \\
\hline & VPV/SA output (kWh) & 10.9 & 12.4 & \\
\hline & Total solar collection $(\mathrm{kWh})$ & 36.5 & 37.3 & $2.3 \%$ \\
\hline Summer & Fans and pumps (kWh) & 16.3 & 10.6 & \\
\hline \multirow[t]{5}{*}{ (July 26, 2002) } & Boiler input (kWh) & 9.5 & 0.0 & \\
\hline & Total consumption $(\mathrm{kWh})$ & 25.8 & 10.6 & $-59.0 \%$ \\
\hline & EvacTube output (kWh) & 30.3 & 33.3 & \\
\hline & VPV/SA output (kWh) & 8.0 & 0.0 & \\
\hline & Total solar collection (kWh) & 38.4 & 33.3 & $-13.3 \%$ \\
\hline
\end{tabular}

The existing prototype building has a building energy management system programmed according to emerging engineering practice for a building of this type. This control schedule was taken as the benchmark against which the calculated performance of alternative control schemes could be measured. The combination of online modeling of the performance of the building and its systems, together with an optimization algorithm that is capable of devising optimal or near-optimal supervisory control trajectories, is shown to have potential in an application where a historical legacy of engineering experience cannot be drawn upon.

The project has served as proof that, given further development, an optimal or near-optimal control scheme can be found using a combination of a detailed system model and an evolutionary optimization method. Its applicability to other situations hinges primarily on the critical stage of devising a system model that accurately represents the behavior of the prototype. The advantage of a combined simulation/optimization approach is that the provision of domain-specific knowledge to the optimization process on the part of the controls designer is limited.

The final stages of this project were planned to include an online implementation of the optimal control approach in the prototype building. This would have needed significant further development to improve the execution time of the system model. Unfortunately, resources were not available to carry this out.

\section{ACKNOWLEDGMENT}

The authors would like to acknowledge the financial support of the Engineering and Physical Sciences Research Council (EPSRC) under grant GR/S30467 and the collaboration of Trend Control Systems, Ltd., and the Oadby and Wigston District Council. 


\section{REFERENCES}

Brandemuehl, M.J. 1993. HVAC 2 Toolkit-Algorithms and Subroutines for Secondary HVAC System Energy Calculations. Atlanta: American Society of Heating, Refrigerating and Air-Conditioning Engineers, Inc.

Cartmell, B. 2004. The energy saving potential of multi-operational ventilated photovoltaic systems in the built environment. $\mathrm{PhD}$ thesis, De Montfort University, Leicester, UK.

Crabb, J.A., N. Murdoch, and J.M. Penman. 1987. A simplified thermal response model. Building Services Engineering Research and Technology 8(1):13-19.

Fong, K.F., T.T. Chow, and V.I. Hanby. 2005. Development of optimal design of a solar water heating system by using evolutionary algorithm. Proceedings of ISEC 2005, International Solar Energy Conference, Orlando, FL.

Goldberg, D.A. 1989. Genetic Algorithms in Search, Optimization and Machine Learning. New York: Addison-Wesley.

Hanby, V.I., and G. Li. 1997. Modeling the thermal and emissions performance of commercial boilers. $H V A C \& R$ Research 3(2):101-11.

Hanby, V.I., D.W. Fletcher, and D.N.T. Jones. 2002. Optimal supervisory control of refrigeration plant by evolutionary algorithm. Proceedings of System Simulation in Buildings '02, Liege, Belgium, University of Liege.

Henze, G.P., D.E. Kalz, S. Liu, and C. Felsman. 2005. Experimental analysis of model-based predictive optimal control for active and passive thermal storage inventory. HVAC\&R Research 11(2):189-213.

Keeney, K.R., and J.E. Braun. 1996. A simplified method for determining optimal cooling control strategies for thermal storage in building mass. $H V A C \& R$ Research 2(1):463-69.

Kelly, G.E. 1988. Control system simulation in North America. Energy and Buildings 10:193-202.

Mathworks. 2005. Simulink® Documentation. http://mathworks.com/access/helpdesk/help/toolbox /simulink. Mathworks, Natick, MA.

Morris, F.B, J.E. Braun, and S.J. Treado. 1994. Experimental and simulated performance of optimal control of building thermal storage. ASHRAE Transactions 100(1):402-14.

Newton, B.J., M. Schmid, J.W. Mitchell, and W.A. Beckman. 1995. Storage tank models. Solar Engineering 2:1111-16.

Ren, M.J., and J.A. Wright. 1997. Predictive optimal control of fabric thermal storage systems. Proceedings of Fifth International IBPSA Conference, Prague, Czech Republic 2:71-78.

Runarsson, T.P., and X. Yao. 2000. Stochastic ranking for constrained evolutionary optimization. IEEE Transactions on Evolutionary Computation 4(3):284-94.

Sun, J., and A. Reddy. 2005. Optimal control of building HVAC\&R systems using complete simulation-based sequential quadratic programming (CSB-SQP). Building and Environment 40:657-69.

Thermomax. 2006. Thermomax Collector Efficiency. http://www.thermomax.com/Efficiency.php.

Wang, S., and X. Jin. 2000. Model-based optimal control of VAV air-conditioning system using genetic algorithm. Building and Environment 35:471-87.

Van Schijndel, A.W.M. 2002. Optimal operation of a hospital power plant. Energy and Buildings 34:1055-65.

Wright, J.A., and V.I. Hanby. 1987. The formulation, characteristics, and solution of HVAC system optimized design problems. ASHRAE Transactions 92(2):702-15. 